R. Patuelli, D.A. Griffith, M. Tiefelsdorf, P. Nijkamp

Spatial filtering and eigenvector stability : space-time model for German unemployment data

Quaderno N. 09-02

Decanato della Facoltà di Scienze economiche

Via G. Buffi, $13 \mathrm{CH}-6900$ Lugano 


\title{
Spatial Filtering and Eigenvector Stability: Space-Time Models for German Unemployment Data
}

\author{
Roberto Patuelli, ${ }^{1}$ Daniel A. Griffith, ${ }^{2}$ Michael Tiefelsdorf ${ }^{2}$ and Peter Nijkamp ${ }^{3}$
}

${ }^{1}$ Institute for Economic Research (IRE), University of Lugano, Switzerland

The Rimini Centre for Economic Analysis, Italy. Email: roberto.patuelli@1u.unisi.ch

${ }^{2}$ School of Economic, Political and Policy Sciences, University of Texas at Dallas, USA

${ }^{3}$ Department of Spatial Economics, VU University Amsterdam, The Netherlands

\begin{abstract}
Regions, independent of their geographic level of aggregation, are known to be interrelated partly due to their relative locations. Similar economic performance among regions can be attributed to proximity. Consequently, a proper understanding, and accounting, of spatial liaisons is needed in order to effectively forecast regional economic variables. Several spatial econometric techniques are available in the literature, which deal with the spatial autocorrelation in geographically-referenced data. The experiments carried out in this paper are concerned with the analysis of the spatial autocorrelation observed for unemployment rates in 439 NUTS-3 German districts. We employ a semi-parametric approach - spatial filtering - in order to uncover spatial patterns that are consistently significant over time. We first provide a brief overview of the spatial filtering method and illustrate the data set. Subsequently, we describe the empirical application carried out: that is, the spatial filtering analysis of regional unemployment rates in Germany. Furthermore, we exploit the resulting spatial filter as an explanatory variable in a panel modelling framework. Additional explanatory variables, such as average daily wages, are used in concurrence with the spatial filter. Our experiments show that the computed spatial filters account for most of the residual spatial autocorrelation in the data.
\end{abstract}

JEL classification: C33, E24, R12

Keywords: spatial filtering, eigenvectors, Germany, unemployment

\section{Introduction}

Noise and shocks in regional labour markets are not symmetrically distributed in space. Moreover, regions can be seen as small open systems. Consequently, they can be expected to have a great level of reciprocal interaction and to influence each other's economic performance (we can think of, for example, regional spillovers). As a result, spatial matters should be considered of critical importance not only when studying socio-economic phenomena (see, for example, Bockstael 1996; Weinhold 2002), but also because of their implications for policymaking (Lacombe 2004).

Correlation and heterogeneity 'in space' among regions are evident in most countries; a key example is Germany, particularly because of its still-existing East/West (EW) economic divide. This former EW divide is the most relevant spatial structure in defining German regional inequalities. To account for the presence of spatial structures that influence (positively or negatively) observable economic entities, such as unemployment or trade, implies a call for a rigorous and systematic assessment of their impact and extent. 
Accordingly, their inclusion in econometric models is necessary in order to correctly assess economic relationships: for example (as observed in this paper), the one between unemployment rates and a set of explanatory variables.

Spatial autocorrelation (SAC) (Cliff and Ord 1981) is the correlation, computed among the values of a single georeferenced variable, that is attributable to the geographic proximity of the objects to which the values are attached. The introduction of the SAC concept was a departure from the classical assumption of independence of the observations constituting a single variable. SAC also complements the concept of temporal autocorrelation, which has been extensively studied and dealt with in time-series econometrics. SAC measures, such as Moran's I (the Moran Coefficient) or Geary's $c$ (the Geary Ratio), are used to quantify the nature and degree of the spatial correlation within a variable, or to test the assumption of independence or randomness.

From a statistical analysis viewpoint, spatial correlation patterns are problematic, since they make standard statistics, such as variances and/or ordinary least squares (OLS) estimators, potentially inappropriate. In particular, spatially correlated values of a variable make the estimator of the error variance - in an OLS framework - biased. This is the case when we analyse regional labour market variables such as unemployment. The uneven geographical localization of regional unemployment observed in countries such as Germany (see for example, Bayer and Juessen 2007) may be caused by spatial effects that concern the variable itself. As a result, a linear, non-spatial model, estimated with OLS, has biased regression parameter estimates. In spatial econometrics, 'spatial lag' models are used to accommodate this problem. If spatial effects were to be related to significant unobserved variables - thus causing SAC in a model's error term - the test statistics of the coefficients would be invalid. In this case, a 'spatial error' model is employed in the literature. More general spatial econometric specifications can be attempted, such as the Cliff-Ord-type model (for a taxonomy of spatial econometric models, see, for example, Anselin 1988).

In this paper, we investigate the importance of spatial effects in German regional labour markets by developing a single-equation, three-variable regional unemployment model. The focus is not on testing a particular theory or model, but rather on the exploration of spatial patterns, in particular in the case where covariates are included. The aim of the paper is twofold: (a) to provide an assessment of how important spatial effects are in explaining German regional unemployment levels and to show that (subsets of) these patterns are consistent over time; and, (b) to develop an econometric model that exploits such consistent spatial patterns in order to improve statistical inference. As an alternative to conventional spatial econometric modelling, we present analyses carried out by means of a semi-parametric 'spatial filtering' technique (described in Griffith 2003), which is based on the decomposition of spatial weights matrices.

The remainder of the paper is structured as follows. Section 2 provides a brief overview of the spatial filtering method, while Section 3 illustrates the data set available. Section 4 describes the empirical application carried out: that is, the spatial filtering analysis of regional unemployment rates in Germany, along with the introduction of socio-economic covariates in the spatial filtering framework. Finally, Section 5 offers some summary information and concluding remarks, as well as future research directions.

\section{The Spatial Filtering Framework}

A wide array of methods, as well as several dedicated 'spatial' econometric procedures (see, for example, Anselin et al. 2004), for the statistical analysis of georeferenced data are available in the literature. These techniques are useful when analysing regional unemployment data, such as the case study analysed here, and, particularly, when the final 
aim is to develop forecasting models for some regional scale. Among conventional spatial econometric methods, spatial autoregression (see, among others, Anselin 1988; Griffith 1988) is one method commonly employed. Spatial autoregressive techniques take into account spatial effects using spatial weights matrices (conventionally referred to as $\mathbf{W}$ ). These matrices measure the spatial linkages (dependence) between the values of a georeferenced variable, in terms of geographical contiguity (shared boundaries), distance (between areal unit centroids), or alternative specifications of proximity (for example, social/cultural distance). A general notation for the spatial autoregressive model, which is known as the Cliff-Ord-type model, has been proposed by Anselin (1988):

$$
\begin{aligned}
& y=\rho \mathbf{W}_{1} y+\mathbf{X} \beta+u, \\
& u=\lambda \mathbf{W}_{2} u+\varepsilon, \\
& \varepsilon \sim(0, \Omega) .
\end{aligned}
$$

where $\mathbf{W}_{1}$ and $\mathbf{W}_{2}$ are two (potentially identical) spatial weights matrices. The first equation posits a spatial lag component, whereas the second equation posits a spatial error term. Models belonging to this generic family can be estimated either by (quasi-)maximum likelihood (ML), as described in Anselin $(1988,2001)$ and Lee (2004), or by the generalized method of moments (GMM; see Kelejian and Prucha 1998, 1999; Anselin 2001). These estimators assume that the (spatial) autocorrelation pattern can be combined/concentrated in one or two parameters, and that the spatial weights matrix $\mathbf{W}$ adequately describes the spatial interdependence.

An alternative approach to spatial autoregression is the use of spatial filtering techniques, such as the ones described in Griffith (1981) and Haining (1991), Getis and Griffith (2002), and Tiefelsdorf and Griffith (2006). The main advantage of these filtering procedures is that the studied variables (which are - initially - spatially correlated) are split into spatial and nonspatial components, which then can be employed in an OLS modelling framework. In addition, filtering out spatially autocorrelated patterns enables one to reduce the stochastic noise normally found in the residuals of standard statistical methods such as OLS. This conversion procedure requires the computation of 'spatial filters.' In this paper, we employ the approach developed by Griffith $(1996,2000)$, which is briefly described here. This approach is preferred, in our case study, to the one by Getis (1990, 1995), which requires variables with a natural origin and a linear model specification. Consequently, rates, percentage changes, and so on, can not be used in the Getis approach.

The spatial filtering technique introduced by Griffith is based on the computational formula of Moran's I (MI) statistic. ${ }^{1}$ This methodology exploits eigenvector decomposition techniques, which extract orthogonal and uncorrelated numerical components from a $N$ x $N$ matrix (Tiefelsdorf and Boots 1995). ${ }^{2}$ These components can be seen as independent map

1 Moran's $I$ is the preferred, and oldest, indicator of SAC. It is calculated as:

$I=\frac{N \sum_{i} \sum_{j} w_{i, j}\left(x_{i}-\bar{x}\right)\left(x_{j}-\bar{x}\right)}{\left(\sum_{i} \sum_{j} w_{i, j}\right) \sum_{i}\left(x_{i}-\bar{x}\right)^{2}}$,

where: $n$ is the number of cases; $x_{i}$ is the value of variable $X$ at location $i$; and $w_{i, j}$ is the cell $(i, j)$ of the spatial weights matrix $\mathbf{W}$ considered. Positive autocorrelation $\left(I>-(N-1)^{-1}\right)$ implies that geographical proximity tends to produce similar values of the variable examined. This is a phenomenon that often is observed in reality, especially in economics. Negative SAC $\left(I<-(N-1)^{-1}\right)$ is a much rarer phenomenon.

2 Griffith's spatial filtering techniques may be compared to principal components analysis (PCA), as in fact both methodologies generate orthogonal and uncorrelated new 'variables' that can be employed in a regression analysis framework. Nevertheless, the components derived in PCA have an economic interpretation, because 
patterns, and represent the latent SAC of a georeferenced variable, according to a given spatial weights matrix. They also can be interpreted as redundant information due to spatial interdependencies, in the framework of standard regression analysis.

Formally, these orthogonal components are the computed eigenvectors of the modified spatial weights matrix:

$$
\left(\mathbf{I}-\mathbf{1 1} \mathbf{T}^{\mathrm{T}} / N\right) \mathbf{W}\left(\mathbf{I}-\mathbf{1 1}^{\mathrm{T}} / N\right)
$$

where $\mathbf{I}$ is an identity matrix of dimension $N \times N$, and $\mathbf{1}$ is an $N \times 1$ vector containing 1 's. The eigenvectors of the modified matrix are computed, in sequence, to maximize the sequential residual MI values. The first computed eigenvector, $\mathrm{E}_{1}$, is, therefore, the one whose numerical values generate the largest MI value among all eigenvectors of the modified matrix. Similarly, the second eigenvector, $E_{2}$, is the set of numerical values that, again, maximize the MI value, while being orthogonal and uncorrelated with $\mathrm{E}_{1}$. The process continues until $N$ eigenvectors have been computed. This is the complete set of all possible (mutually) orthogonal and uncorrelated map patterns (Getis and Griffith 2002). When employed as regressors, these eigenvectors may function as proxies for missing explanatory variables.

However, employing all $N$ eigenvectors in a regression framework is not desirable for reasons of model parsimony and statistical significance, and is altogether impossible in a cross-sectional framework, since the number of explanatory variables would be equal to or greater than the number of observations. A smaller set of 'candidate' eigenvectors can be selected from the $N$ eigenvectors, on the basis of their MI values. A pre-specified threshold value can be used for selection screening purposes. Since the eigenvectors are both orthogonal and uncorrelated, a stepwise procedure for linear regression can be used to achieve this end. In this framework, the advantage given by the orthogonality of the eigenvectors is the absence of partial correlations and, therefore, of multicollinearity issues.

The residuals obtained with a stepwise regression constitute the spatially filtered component of the georeferenced variable examined. Each eigenvector selected for inclusion is considered to be part of a 'spatial filter' for the dependent variable. The top two eigenvectors computed $\left(\mathrm{E}_{1}\right.$ and $\left.\mathrm{E}_{2}\right)$ often identify map patterns relating to the underlying geocoding reference axes (for example, major North-South and East-West patterns). Eigenvectors with intermediate values of MI display regional map patterns, whereas eigenvectors with smaller values of MI display local map patterns. A linear combination of the above eigenvectors can be defined as the spatial filter for the variable examined.

The preceding spatial filters are computed on the basis of a modified spatial weights matrix. Formally, a geographic weights matrix is a (squared) $N$ x $N$ matrix containing, most often, binary values $(0$ and 1$)$. A value of 1 for the generic cell $(i, j)$ implies that the two georeferenced objects (for example, regions) $i$ and $j$ are neighbours. The opposite applies for the value 0 . The choice of the matrix to be used is relevant with regard to: (a) the definition of proximity; (b) the variable chosen (if necessary) to indicate proximity; and, (c) the coding scheme employed in the calculation of the matrix. These aspects are critical in defining the spatial weights matrix and the related spatial filter. Patuelli et al. (2006b) address such issues more extensively, with reference to the German regional labour markets case. They test five different spatial weights matrix specifications.

On the basis of the aforementioned study, we select, for the present paper, only one spatial weights matrix, which is based on the rook's contiguity definition (that is, on shared

eigenvectors are used to construct linear combinations of attribute variables, whereas spatial filters are linear combinations of the eigenvectors themselves. As such, the latter should be regarded mostly as patterns of independent spatial dimensions. 
boundaries), and coded according to the so-called C-coding scheme. This scheme is commonly used in spatial statistics and yields a symmetric maxtrix $\mathbf{W}$. It is referred to as a 'globally standardizing' scheme, and it tends to emphasize spatial objects with a greater linkage degree (see Tiefelsdorf and Griffith 2007). As a result of the coding scheme choice, our matrix can be expected to present stronger patterns in the inner study area when compared with alternative schemes, such as the common row-standardized W-coding scheme (which will show more 'extreme' values along the edges of a study area).

\section{The Data}

This paper presents results based on the analysis of German unemployment data (unemployment rates). The dataset employed in our experiments consists of a panel of 439 German districts (kreise), for which the years from 1996 to 2002 are available, while the level of aggregation of the dataset is NUTS-3. This aggregation level enables a more detailed examination of 'local' unemployment patterns. Data at the NUTS-2 level would have only 41 regions (Regierungsbezirke). Alternatively, an intermediate approach is proposed by Kosfeld and Dreger (2006), who carry out a spatial filtering analysis of German regional labour market data using 180 regional labour market areas (defined in Eckey 2001).

In addition to our dependent variable (unemployment rates), we employ information at the same aggregation level about: (a) regional daily wages of full-time workers; (b) number of full-time employees; and, (c) working-age population. For the analysis presented in Section 4.3, we employ these three variables over the period from 1994 to and including 2001.

The data are provided by the German Institute for Employment Research (Institut für Arbeitsmarkt- und Berufsforschung, IAB), and cover the entire German territory, consisting of 326 districts in the former West Germany, and 113 in the former East Germany. While longer data series are available - for all the aforementioned variables - for West Germany, East German data only became available after reunification. Therefore, if a comprehensive analysis for all of Germany is to be carried out, the time span of our data is limited to the aforementioned periods.

\section{The Empirical Application: Computation and Choice of Spatial Filters for German Unemployment Modelling}

\subsection{Spatial Analysis of Regional Unemployment}

Analysing unemployment rates and their geographic distribution is of great interest because, in particular, of their relevance in the determination of welfare policies, and they serve as indicators of socio-economic performance (López-Bazo et al. 2002; Cracolici et al. 2007; Patuelli 2007). The importance of spatial matters in regional labour markets, specifically with regard to the case of Germany, has been highlighted recently in various articles (see, for example, Niebuhr 2003; Elhorst et al. 2007; Longhi and Nijkamp 2007). Kosfeld and Dreger (2006) show that consideration of spatial dependencies is needed in order to correctly estimate unemployment and employment thresholds in their relationship with changes in production levels. Patuelli et al. (2006a) report improved performance in the forecast of regional employment variations by means of neural networks upon employing explanatory variables related to geographical contiguity (spatial shift-share). Numerous further examples apply.

Moreover, a number of economic variables measured at the regional scale exhibit strong spatial heterogeneity, mostly because of the coexistence - in the case of Germany - of highly performing areas such as Bavaria, and lowly performing areas such as the former East 
Germany. If this spatial heterogeneity can be (in part) traced back to the relationships of proximity between regions, it can be modelled according to proximity itself. In particular, a description of the spatial patterns underlying yearly aggregate observations of the same variable may help forecast future values and provide a visual description of time-invariant spatial patterns (see Griffith and Paelinck 2009).

\subsection{Spatial Filtering of Unemployment}

\subsubsection{Computation and Selection of Spatial Filters over Time}

The first step in the construction of a spatial filter to be applied to the variable of study is the computation of the eigenvectors of the spatial weights matrix, followed by the choice of a subset of 'candidate' eigenvectors from which selection is made. Candidate eigenvectors are selected on the basis of their MI values and their correlations with the georeferenced regional unemployment data. A minimum threshold value of 0.25 for the statistic $\mathrm{MI} / \mathrm{max}(\mathrm{MI})$, which roughly corresponds to 5 per cent of the variance being accounted for in the regression of a generic georeferenced variable $\mathbf{Z}$ on $\mathbf{W Z}$ (), has been used in our case to identify the candidate set. When carried out for a (C-coding scheme, see Section 2) rook's definition of contiguity spatial weights matrix, the computation and selection process described here results in the identification of a set of 98 candidate eigenvectors. The highest MI shown by the eigenvectors (that is, the MI of the first selected eigenvector) is 1.24. To date, only the spatial weights matrix W (in its modified version, see Equation (2)), and not the data, is used for the selection of the eigenvectors.

Once a set of 'candidate' eigenvectors has been selected, its statistical significance, as an explanatory variable for German regional unemployment rates, has to be established. This process is carried out, for each cross-section, by means of a stepwise logistic regression analysis (as in Griffith 2004), estimated in a generalized linear model (GLM) framework using a binomial link function. Because of the GLM estimation, obtained by maximum likelihood (ML), the stepwise regression employed is based on a likelihood measure, namely the Akaike information criterion (AIC). ${ }^{3}$ Similarly, other measures, such as the corrected AIC (McQuarrie and Tsai 1998), which corrects for small samples, could be employed. Because AIC-based stepwise regressions tend to overfit, and consequently to overselect, we carry out a further manual backward elimination of regressors (eigenvectors) on the basis of $\chi^{2}$ tests based on a 95 per cent significance level. This process is expected to finally result in spatially uncorrelated residuals. Consequently, following the notations of Griffith's (2004) and McCullogh et al. (2008), the resulting logistic model for a particular time $t$ is:

$$
E\left(y_{i}\right)=\pi\left(\mathbf{E}_{i, k}\right)=\frac{1}{1+e^{-\left(\alpha+\beta \mathbf{E}_{i, k}\right)}},
$$

where $\pi$ is the mean function, $y_{i}$ is the $i$ th element of the dependent variable $y, \mathbf{E}_{i, k}$ is the $i$ th row of the matrix containing the final set of $k$ eigenvectors selected, and $\alpha$ is a constant. For simplicity, year-specific subscripts are omitted here.

We also cope with overdispersion in the data, which is a frequently experienced phenomenon when analysing economic variables. We adjust for so-called extra-binomial variation by employing Williams's (1982) quasi-likelihood overdispersion adjustment. The

\footnotetext{
3 The Akaike information criterion (AIC) was proposed by Akaike (1974) and is a goodness-of-fit measure based on the concept of entropy. The AIC takes into account the trade-off between model complexity and model fit. It is calculated as: $A I C=2 k-2 \ln (L)$, where $k$ is the number of estimated parameters and $L$ is the likelihood function of the estimated model.
} 
method postulates 'a source of extra-binomial random variation between observations' (Williams 1982, p. 144), and iteratively estimates the dispersion parameter associated with the data, adjusting the GLM weights accordingly. ${ }^{4}$

The same process is repeated for all years of available data - from 1996 to 2002 for the aforementioned C-coding scheme with the rook's definition of contiguity spatial weights matrix. Consequently, seven sets of 'significant' eigenvectors (one set for each year) are selected. These are used to construct the 'spatial filters' for each year.

Next, we pinpoint a subset of eigenvectors that is common to the years 1996 to 2002; that is, the subset of eigenvectors that has been selected for all years of data, according to the stepwise procedure described. Detailed results about the eigenvectors selected in each year are given in Table 1. Our results show that we found a set of 22 eigenvectors that are significant, as explanatory variables of regional unemployment, over the entire time period considered.

In terms of statistical relevance, the amount of variance explained by the spatial filtering regressors is fairly consistent over the years (reasonably, unemployment patterns do not change much from year to year). The pseudo- $R^{2}$ values found for these analyses are in the $0.734-0.797$ range. Plots of the observed and estimated unemployment values are shown in Figure 1, for the years 1996 to 2002, and display a fairly good fit, though a tendency toward underestimation can be observed.

As mentioned in Section 2, the constructed spatial filters, which are the linear combinations of the selected eigenvectors using their logistic regression estimated coefficients, can be interpreted not only as potential explanatory variables substituting for missing ones, but also as map patterns. A graphical visualization of the spatial filters uncovered by our analysis provides an example of the map features embedded in the eigenvectors' values. Figure 2 shows the four eigenvectors with the largest MI values computed for the employed contiguity matrix, and that are common to all the years examined $\left(\mathrm{E}_{2}, \mathrm{E}_{4}, \mathrm{E}_{6}\right.$ and $\left.\mathrm{E}_{7}\right)$. As noted previously, the first two eigenvectors for contiguity matrices usually show underlying geocoding reference axis patterns. Spatial filter $(a)\left(E_{2}\right)$ in Figure 2 seems, in fact, to be characterized by a North-South pattern (a 'global' pattern). As we observe the subsequent spatial filter components (b, c, and d), the geographic patterns mapped relate to characteristics of smaller geographical scale, showing patterns that can be categorized first as 'regional', and then as 'local'. Although they may contain some common map patterns (for example, NorthSouth and East-West patterns), spatial filters computed with different spatial weights matrices will vary to some degree..$^{5}$ In addition, results from the application of a 'queen' contiguity definition are not considered here, since the two specifications of adjacency differ by only 25 neighbour links.

\footnotetext{
${ }^{4}$ Because of the GLM weighting, pure orthogonality of the eigenvectors is lost (which may in fact create computational problems). We therefore consider the eigenvectors as quasi-orthogonal when employed in a GLM estimation framework.

5 An in-depth analysis of the issues related to the choice of a coding scheme, particularly in view of the type of data patterns that a spatial analyst wants to emphasize (different coding schemes accentuate different kinds of patterns) goes beyond the scope of this paper; however, an interesting treatment can be found in Tiefelsdorf et al. (1999).
} 


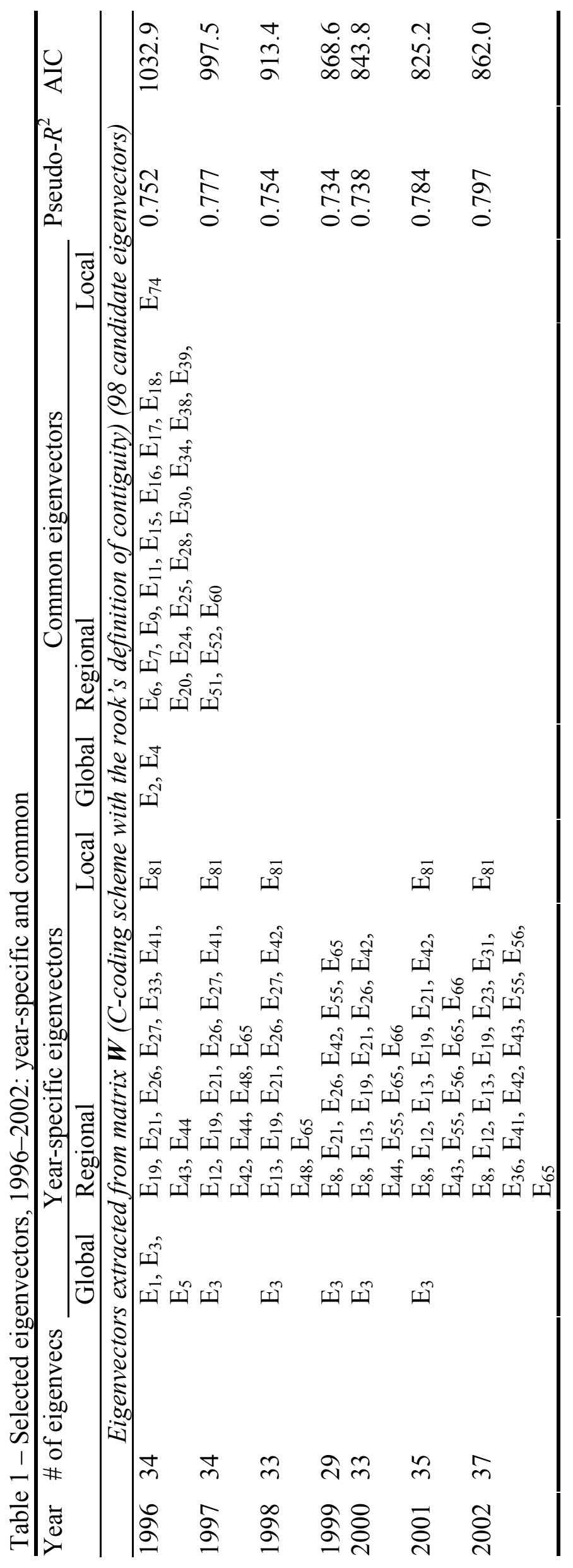



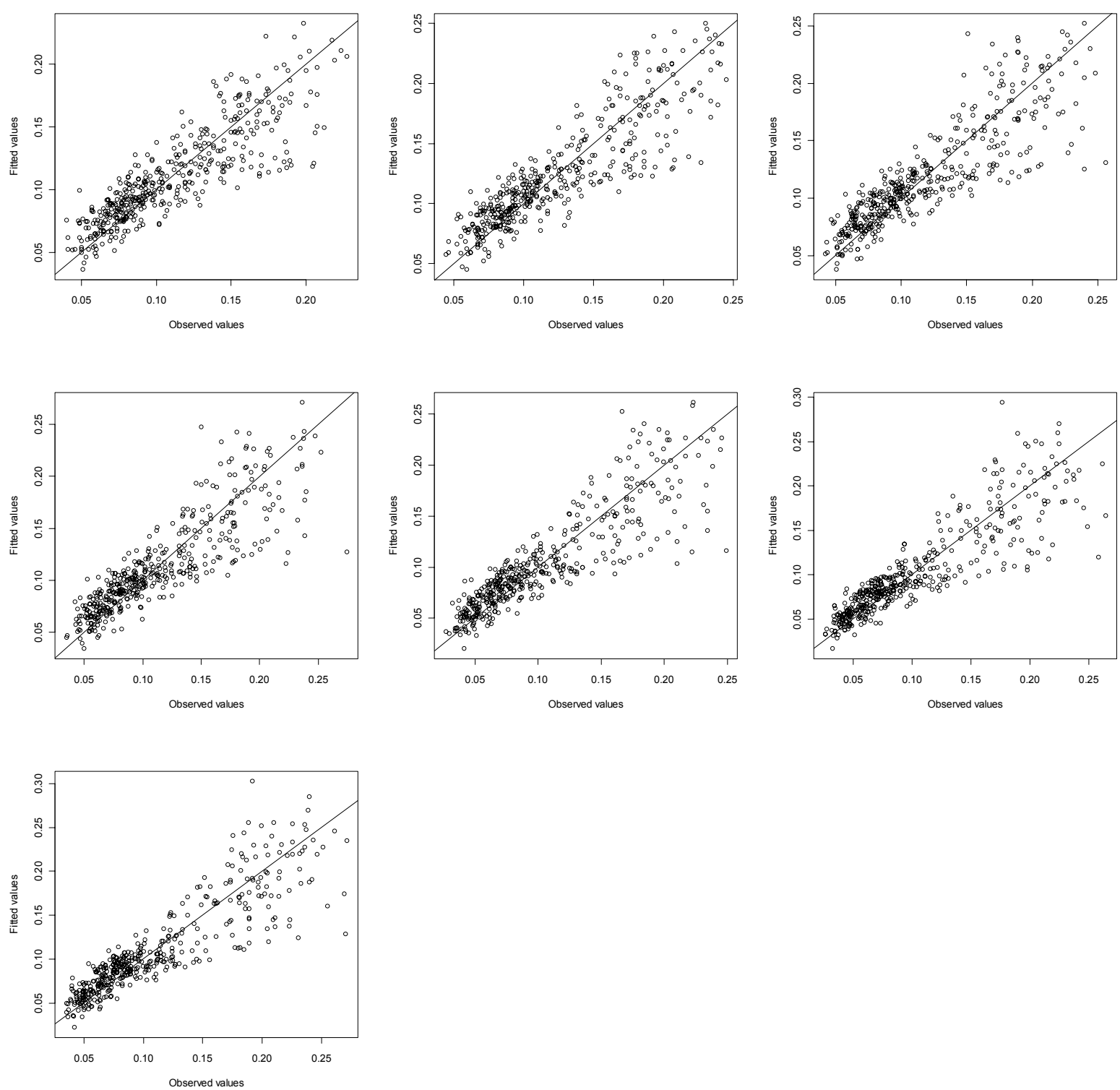

Figure 1 - Plots of observed and fitted values (left to right, top row: 1996, 1997 and 1998; middle row: 1999, 2000 and 2001, bottom row: 2002)

\subsubsection{A Spatial Structured Random Effects Panel Model for German Unemployment}

The preceding section focuses on computing and selecting sets of eigenvectors that are commonly significant for all the years examined (1996-2002). In this section, we exploit these findings by estimating a spatial structured random effects panel model in order to evaluate the explanatory power of a time-invariant spatial filter. We employ a generalized linear mixed model (GLMM), which we develop for the case of the C-coding scheme with the rook's definition of contiguity weights matrix illustrated above. The 22 common selected eigenvectors (see preceding section) are entered as regressors in a generalized linear model (GLM) with a binomial link function, together with a normal-distributed random-effects intercept variable, in order to handle temporal correlation. Conditionally on the random effects, a standard GLM is indeed estimated (Venables and Ripley 2002). A similar analysis is presented in Griffith (2008) for space-time agricultural production. 


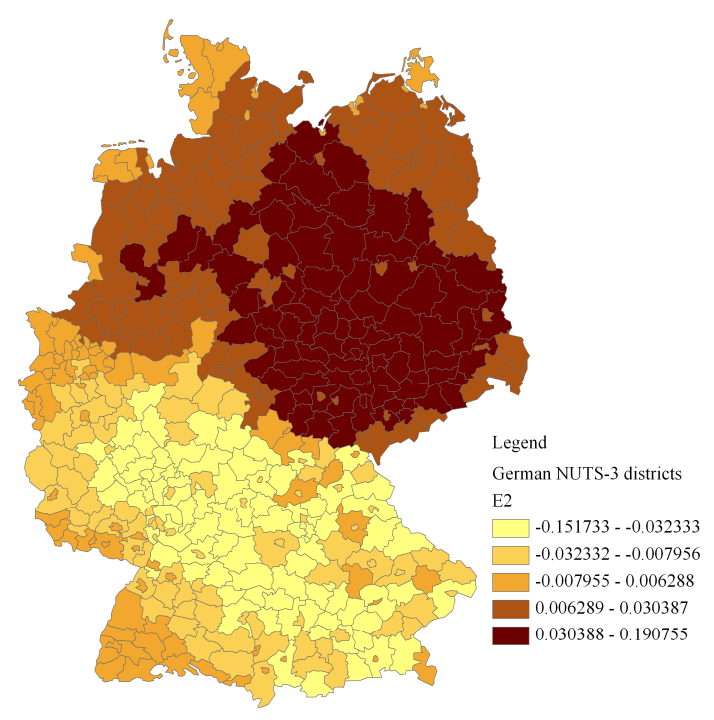

(a)

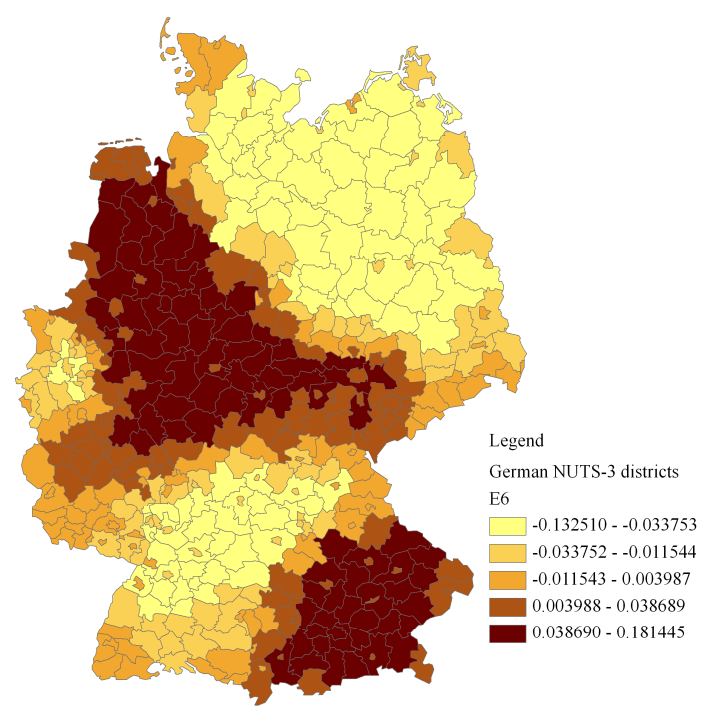

(c)

Figure 2 - Maps of main common eigenvectors $\left(\mathrm{E}_{2}, \mathrm{E}_{4}, \mathrm{E}_{6}, \mathrm{E}_{7}\right)$ according to MI values (Ccoding scheme with the rook's definition of contiguity spatial weights matrix)

In a GLMM, the intercept (of the linear predictor) is specified as a geographically-varying random variable, which accounts for the serial correlation in short time series such as that employed in our case study. This random effects intercept also supports inferences beyond the employed surface partitioning and set of points in time.

Technically, a GLMM can be viewed as a non-linear model whose non-linearity is given by the link function chosen (the logit in our binomial case), and its variance is a function of the mean (Venables and Ripley 2002). We fit our GLMM by means of a penalized quasilikelihood approach (Breslow and Clayton 1993), which makes use of quadratic Taylor expansions (Wolfinger and O'Connell 1993; Evans and Swartz 2000). The chosen estimation method also accounts for extra-binomial variation - similar to Williams's (1982) approach for the year-by-year analyses - by estimating dispersion and adjusting the significance levels accordingly. Table 2 presents summary results regarding the spatial autocorrelation accounted for by this model. 
Table 2 - Spatial autocorrelation measures for German unemployment, based upon the rook's definition of contiguity (C-coding scheme) geographic weights matrix

\begin{tabular}{llll}
\hline \multirow{2}{*}{ Year } & \multicolumn{2}{c}{ Observed values } & \multicolumn{2}{c}{ Spatial filter residuals } & Fitted values \\
\cline { 2 - 4 } & MI & MI & Pseudo-R ${ }^{2}$ \\
\hline 1996 & 0.836 & 0.279 & 0.943 \\
1997 & 0.873 & 0.245 & 0.962 \\
1998 & 0.859 & 0.207 & 0.965 \\
1999 & 0.860 & 0.194 & 0.956 \\
2000 & 0.891 & 0.264 & 0.949 \\
2001 & 0.897 & 0.306 & 0.934 \\
2002 & 0.903 & 0.292 & 0.922 \\
\hline Spatial filter & 1.120 & - & - \\
\hline
\end{tabular}

The statistical results presented in Table 2 show that the spatial filter accounts for a large share of SAC, though not all of it. A graphical visualization of the spatial filter appears in Figure 3. In terms of goodness-of-fit, the model has a pseudo- $R^{2}$ of 0.922 (year-by-year pseudo- $R^{2}$ s are given in Table 2), and all the eigenvectors employed are significant.

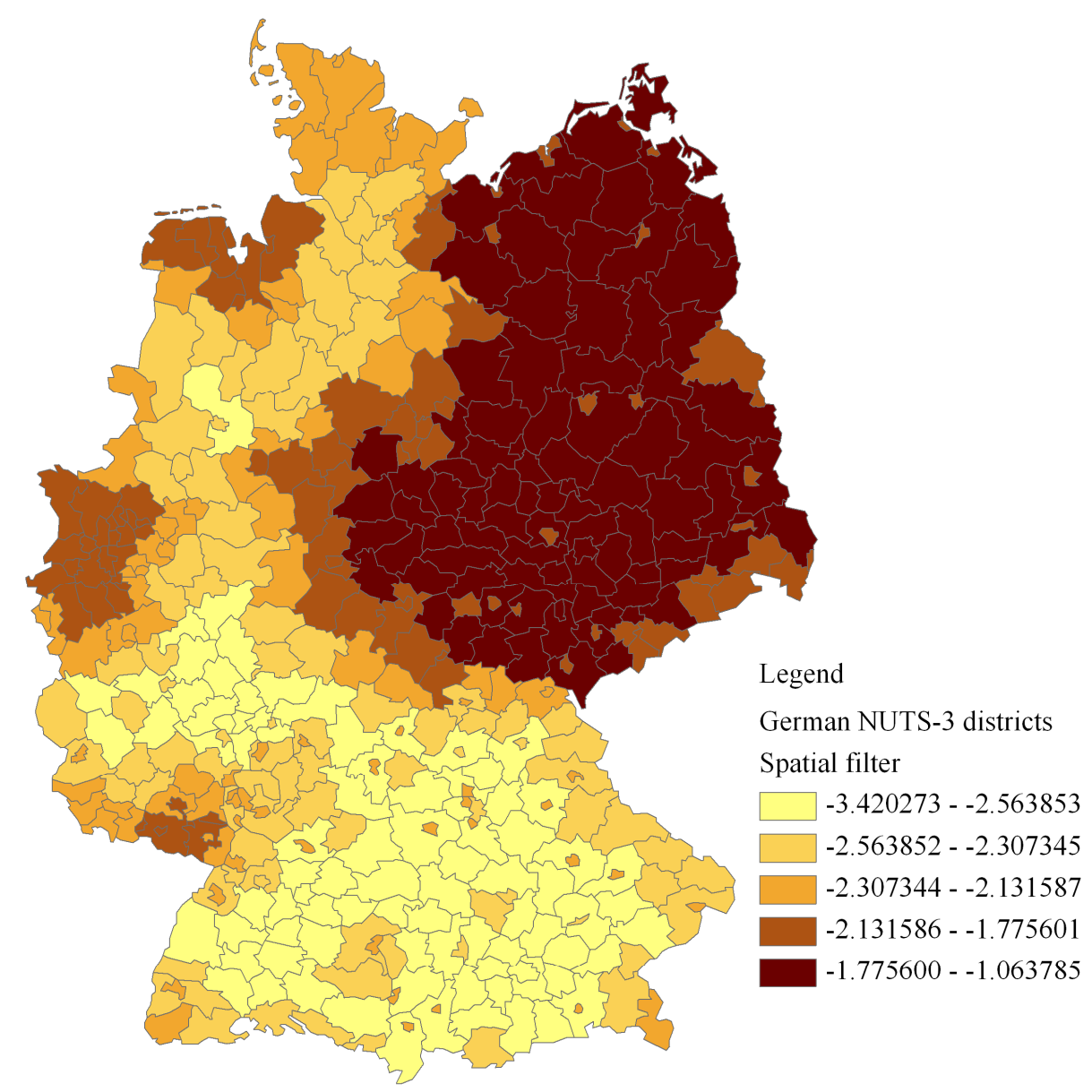

Figure 3 - Graphical visualization of the spatial filter obtained in the case of the rook's definition of contiguity (C-coding scheme) geographic weights matrix, GLMM estimation

While the estimation described above provides comforting results, a further level of analysis is necessary in order to carry out more detailed experiments about the dynamics of 
unemployment patterns. In this regard, the limitation of the experiments presented above is that they refer to an unemployment autoregression. Therefore, we propose the utilization of additional explanatory variables in the model. The joint employment of spatial filters and socio-economic explanatory variables involves further attention to the mechanics of spatial filtering. Eigenvectors that are significant both to the explained and to the explanatory variable(s) also imply filtering of the latter.

\subsection{Inclusion of Explanatory Variables in Spatial Filtering}

\subsubsection{Selection of the Spatial Filters for the Unemployment Models}

The next step in our analysis is to further the preceding spatial statistical treatment by including covariates with socio-economic meaning. By doing so, we fulfil two main objectives: (a) we go beyond the limit of the previous analyses, which account only for the purely geographical distribution of the variable concerned (German unemployment rates); and, (b) we fully exploit the potential of spatial filtering, as we compute new spatial filters. This procedure allows us to obtain spatially adjusted estimates of the regression parameters relating to the real covariates employed.

To include all the factors that may determine regional unemployment differentials as well as the observed spatial patterns in an econometric model is a demanding task. These factors may be socio-economic or locational: spillover effects, as well as rigidities in labour markets (highly unionized workers) or in mobility (high real estate prices). Consequently, an analyst may choose to focus on a few main explanatory variables relating to labour demand and supply, such as employment, population, or wages, in order to explain - as in our case study unemployment variations. The effects of the remaining (excluded) factors - in particular if related to location - might identify a set of spatial structures. With this objective in mind, we include in our analysis three explanatory variables: (a) the number of full-time employed individuals; (b) average daily wages of full-time employees; and, (c) working age population (age 15-65). All data are available for all German regions and at the same level of disaggregation as the dependent variable (that is, NUTS-3).

We develop a simple three-variable unemployment model, as the focus is not on testing a particular theory or model, but rather on exploring the impact and potential of the spatial filtering technique proposed in the case when covariates are included. The revised model estimated is therefore:

$$
\text { unempl }_{i t}=\Delta \text { wage }_{i, t-1}+\Delta e m p l_{i, t-1}+\Delta \text { pop }_{i, t-1}+\varepsilon_{i t},
$$

where unempl $_{i t}$ is the unemployment rate of region $i$ at time $t, \Delta$ wage $_{i, t-1}$ is the variation of wages in the same region in the period $(t-2, t-1), \Delta e m p l_{i, t-1}$ and $\Delta p o p_{i, t-1}$ respectively are the corresponding variations in full-time employment and working-age population for the same period, and $\varepsilon_{i t}$ is the error term. Longer lags, in particular with regard to population variations, could be used (see, for example, Carlino and Mills 1987), but are not considered in our experiments because of the limited period of data availability.

In our model, the wages and employment variables refer to the labour demand factors that influence unemployment. Meanwhile, the population variable can be seen as an indicator of both labour supply and demand factors, because it accounts for several demographic aspects. With regard to labour supply, natural growth and immigration may lead to changes in the age structure of the workers' pool, where a younger working population has been found to experience more persistent unemployment (Elhorst 1995). However, the dataset analysed in this paper is too short to expect such a significant effect to be detectable. Migration, instead, 
may have a neutral effect, if migrants fill vacancies left unfilled, or if they do not join the labour force. With regard to the labour demand effect of changes in population levels, a positive net immigration may induce higher productivity or higher investments if new/higher skills are introduced in a labour market, or simply higher levels of production to satisfy the increased population. As a result of the conflicting effects described, the expected sign for the effect of population change on unemployment is ambiguous.

The expected signs for changes in wages and employment are more straightforward. The negative effect of wage increases on labour demand is expected to lead to increases in the unemployment rates, implying a positive expected sign. The inverse relationship between employment (an indicator of labour demand) and unemployment implies a negative expected sign.

Clearly, the model could be estimated in terms of unemployment rate variations. Although this solution would be more suitable in economic reasoning terms (relating variations in the explanatory variables to variations in the dependent variable), we choose to proceed, as in Section 4.2.1, with the analysis of unemployment rates. As a result, the spatial filters obtained for this model specification are comparable to the ones found for the previous specification presented in the paper. The differences between the new and the old spatial filters may result from inclusion in the model of substantive covariates, for which the spatial filters previously selected were, in part, a surrogate. With the inclusion of spatial filter components (eigenvectors of the modified spatial weights matrix), Equation (4) becomes:

$$
\text { unempl }_{i t}=\Delta \text { wage }_{i, t-1}+\Delta e m p l_{i, t-1}+\Delta \operatorname{pop}_{i, t-1}+s f_{i}+\varepsilon_{i t},
$$

where $s f_{i}$ is the linear combination - for region $i$ - of the selected spatial filter components.

The first step in estimating Equation (5) is to find the appropriate spatial filters for this empirical case. Again, we employ the C-coding scheme with the rook's definition of contiguity geographic weights matrix $\mathbf{W}$ used in Section 4.2.1. We start from the set of 98 candidate eigenvectors, and follow a spatial filter selection procedure similar to the previously employed one: a stepwise logistic regression of Equation (5), where the socio-economic covariates are the initial regressors included (and therefore cannot be dropped in the stepwise selection), and the subsequent inclusion of single eigenvectors as additional regressors is decided on the basis of the model's Akaike information criterion (AIC) during the stepwise procedure, and on the basis of $\chi^{2}$ tests in the manual backward elimination subsequently carried out.

For each year (1996-2002), we compute the spatial filter concerning jointly the dependent and the independent variables. As shown in Table 3, we find spatial filters comprising between 32 and 38 eigenvectors each. The pseudo- $R^{2}$ values of the models are significantly higher than those found in Section 4.2.1: they range from 0.820 to 0.885 . The improved statistical power of the analysis (with respect to the preceding range: $0.734-0.797$ ) is a reasonable finding, since we introduced 'real' explanatory variables. With regard to the spatial filters, the set of eigenvectors common to all years that we find is slightly smaller (21 components) than the previously found set (22 components), as the inclusion of the covariates 'eats up' a share of the variance to be accounted for in the data. 


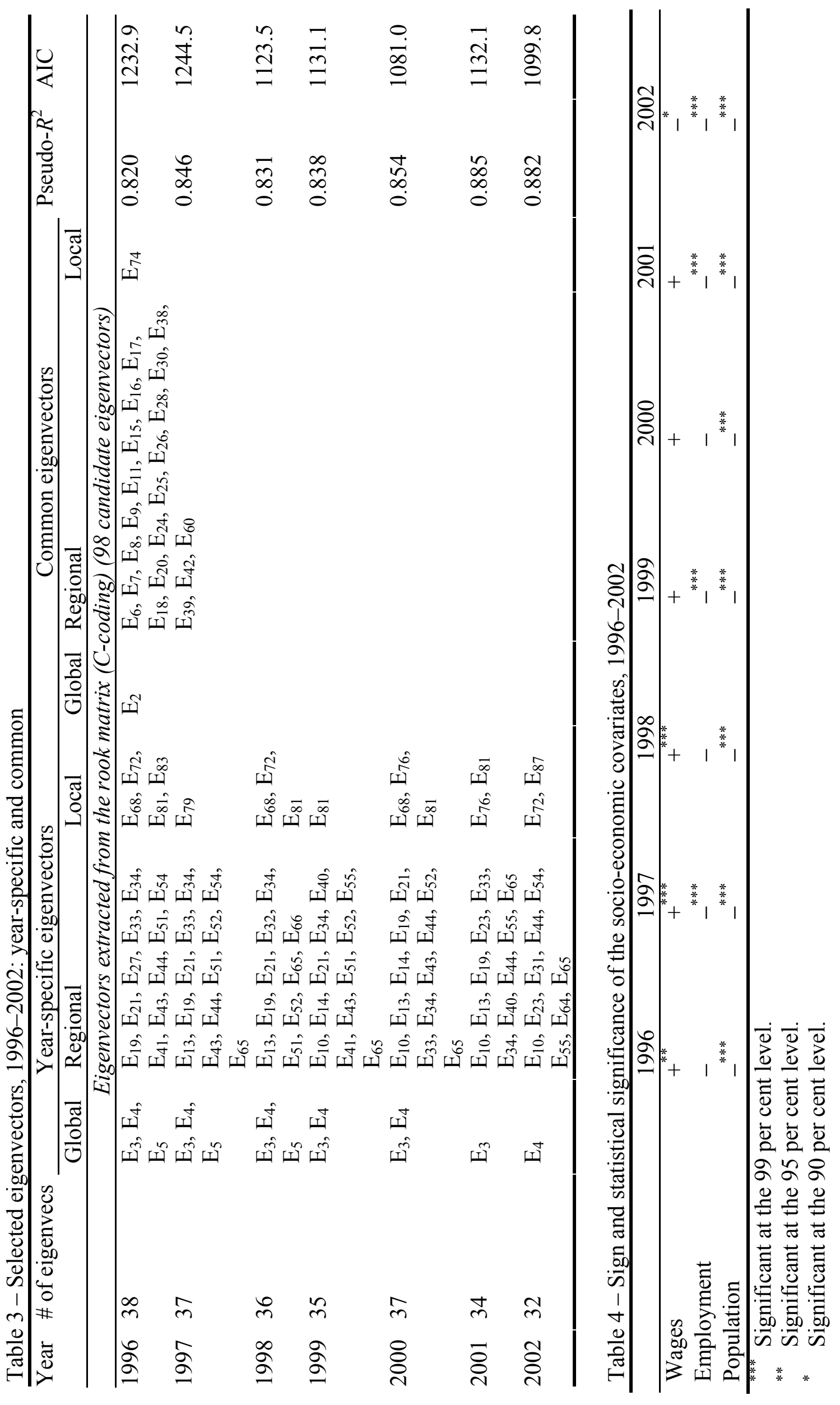


With regard to the explanatory variables employed (wages/employment/population), we observe, in Table 4, that:

- The related regression parameters are mostly significant. While a comparison model comprising only wages, employment and population variations (not shown here) gives just three non-significant parameters, the significance levels of the spatial filter model are still satisfactory, as they generally confirm the relevance of the variables.

- The signs of the explanatory variables are as expected, and constant over the years (aside from the case of wages in 2002). However, the stable result of a negative parameter for the population growth variable appears to suggest a dominance of demand factors with regard to demographic change, and surely deserves further investigation in order to be fully interpreted in this context.

The results presented in Table 3 and Table 4 summarize the statistical power of our spatial filter-enhanced models. We next present the results of the models with regard to SAC. Table 5 summarizes our empirical findings with respect to model residuals. According to the tabulated results, if our naïve unemployment model is carried out without including the spatial filter components, the regression residuals' SAC obtained by the logistic regression for each year range between 0.363 and 0.722 , implying rather strong SAC. The re-computation of the models with the inclusion of the spatial filters decreases SAC, in the range from -0.027 to 0.017. Further, if we re-run our logistic regression models by including, together with the covariates, only the set of common eigenvectors for 1996-2002, we find residual SAC varying between 0.170 and 0.240 , implying a loss in the SAC abatement power of about 0.20 between the full yearly spatial filters and the time-invariant spatial filter. This is the compromise we accept by selecting a common spatial filter for the entire dataset.

Table 5 - Spatial autocorrelation of model residuals, 1996-2002

\begin{tabular}{llllllllllllllllll}
\hline & 1996 & & 1997 & & 1998 & & 1999 & & 2000 & & 2001 & & 2002 \\
& \cline { 2 - 14 } & MI & Pr & MI & Pr & MI & Pr & MI & Pr & MI & Pr & MI & Pr & MI & Pr \\
\hline GLM & 0.603 & 0.000 & 0.577 & 0.000 & 0.578 & 0.000 & 0.652 & 0.000 & 0.722 & 0.000 & 0.451 & 0.000 & 0.363 & 0.000 \\
GLM-SF & 0.006 & 0.780 & 0.001 & 0.903 & -0.012 & 0.755 & 0.003 & 0.862 & -0.013 & 0.710 & -0.027 & 0.398 & 0.017 & 0.527 \\
GLM-SF RD & 0.193 & 0.000 & 0.207 & 0.000 & 0.185 & 0.000 & 0.170 & 0.000 & 0.211 & 0.000 & 0.206 & 0.000 & 0.240 & 0.000 \\
GLM-SF RD ALL & 0.190 & 0.000 & 0.180 & 0.000 & 0.162 & 0.000 & 0.188 & 0.000 & 0.279 & 0.000 & 0.231 & 0.000 & 0.204 & 0.000 \\
GLMM-SF RD & 0.266 & 0.000 & 0.267 & 0.000 & 0.229 & 0.000 & 0.206 & 0.000 & 0.275 & 0.000 & 0.281 & 0.000 & 0.275 & 0.000 \\
\hline
\end{tabular}

Notes: GLM uses only the three covariates; GLM-SF uses the covariates and the selected eigenvectors (year by year); GLM-SF RD uses the covariates and the reduced set of eigenvectors common to the seven years; GLM-SF RD ALL uses the entire panel and the common eigenvectors, but ignoring the repeated measurements correlation; GLMM-SF RD uses the entire panel and the common eigenvectors, and random effects (see next section).

Given the above results, the next necessary step is to exploit the time-invariant spatial filter found in Table 3 in a wider framework.

\subsubsection{A Spatial Filtering Panel Model for German Unemployment}

The analyses carried out on the joint inclusion, in a logistic regression framework, of our socio-economic explanatory variables and spatial filter components show that acceptably low levels of SAC can be reached by replacing the spatial filters separately computed for each year with one spatial filter common to all years. The advantage of employing this reduced set of eigenvectors (see Table 3) is that it can be employed in the GLMM framework previously outlined in Section 4.2.2. 
As in our first GLMM approach, the German regional unemployment rates are the dependent variable, while our three economic covariates (wages, employment and population), as well as the spatial filter selected in Section 4.3.1, serve as explanatory variables. The results of our new GLMM estimation are presented in Table 6, while a graphical visualization of the emerging spatial filter can be seen in Figure 4.

Table 6 - GLMM parameter estimates, 1996-2002

\begin{tabular}{|c|c|c|c|c|}
\hline Parameter & Value & Std.Error & $t$-value & $p$-value \\
\hline Intercept & -0.658 & 0.317 & -2.079 & $0.038^{* *}$ \\
\hline Wages & 0.375 & 0.119 & 3.137 & $0.002^{* * *}$ \\
\hline Employment & -2.037 & 0.082 & -24.867 & $0.000^{* * *}$ \\
\hline Population & 0.119 & 0.340 & 0.350 & 0.726 \\
\hline $\mathrm{E}_{2}$ & 7.409 & 0.246 & 30.146 & $0.000^{* * *}$ \\
\hline $\mathrm{E}_{6}$ & -2.279 & 0.246 & -9.268 & $0.000^{* * *}$ \\
\hline $\mathrm{E}_{7}$ & 0.894 & 0.246 & 3.641 & $0.000^{* * *}$ \\
\hline $\mathrm{E}_{8}$ & 0.888 & 0.245 & 3.617 & $0.000^{* * *}$ \\
\hline $\mathrm{E}_{9}$ & 1.669 & 0.245 & 6.825 & $0.000^{* * *}$ \\
\hline $\mathrm{E}_{11}$ & -0.873 & 0.245 & -3.556 & $0.000^{* * *}$ \\
\hline$E_{15}$ & -1.882 & 0.245 & -7.681 & $0.000^{* * *}$ \\
\hline$E_{16}$ & 0.828 & 0.245 & 3.385 & $0.001^{* * *}$ \\
\hline $\mathrm{E}_{17}$ & -0.888 & 0.246 & -3.611 & $0.000^{* * *}$ \\
\hline $\mathrm{E}_{18}$ & 1.006 & 0.245 & 4.103 & $0.000^{* * *}$ \\
\hline $\mathrm{E}_{20}$ & -0.805 & 0.246 & -3.273 & $0.001^{* * * *}$ \\
\hline$E_{24}$ & -0.988 & 0.245 & -4.033 & $0.000^{* * *}$ \\
\hline$E_{25}$ & 0.652 & 0.244 & 2.667 & $0.008^{* * *}$ \\
\hline$E_{26}$ & -0.765 & 0.246 & -3.110 & $0.002^{* * *}$ \\
\hline $\mathrm{E}_{28}$ & 0.877 & 0.244 & 3.590 & $0.000^{* * *}$ \\
\hline $\mathrm{E}_{30}$ & -1.041 & 0.245 & -4.248 & $0.000^{* * *}$ \\
\hline $\mathrm{E}_{38}$ & -0.625 & 0.245 & -2.556 & $0.011^{* *}$ \\
\hline$E_{39}$ & 0.825 & 0.245 & 3.370 & $0.001^{* * *}$ \\
\hline $\mathrm{E}_{42}$ & 0.586 & 0.244 & 2.401 & $0.017^{* *}$ \\
\hline $\mathrm{E}_{60}$ & 0.562 & 0.245 & 2.293 & $0.022^{* *}$ \\
\hline$E_{74}$ & -0.528 & 0.245 & -2.158 & $0.032^{* *}$ \\
\hline
\end{tabular}

${ }_{* * *}^{* *}$ Significant at the 99 per cent level.

** Significant at the 95 per cent level.

Not surprisingly, the map visualization of the spatial filter emerging from our GLMM estimation outlines a clear contrast between the former West and East Germany. This finding was to be expected, since our analysis is concerned with the levels of regional unemployment, (rather than with variations in it). As a result, the spatial filter takes into account the stock of unemployment that is not explained by recent labour market trends (that is, the stock acquired prior to the time period examined). 


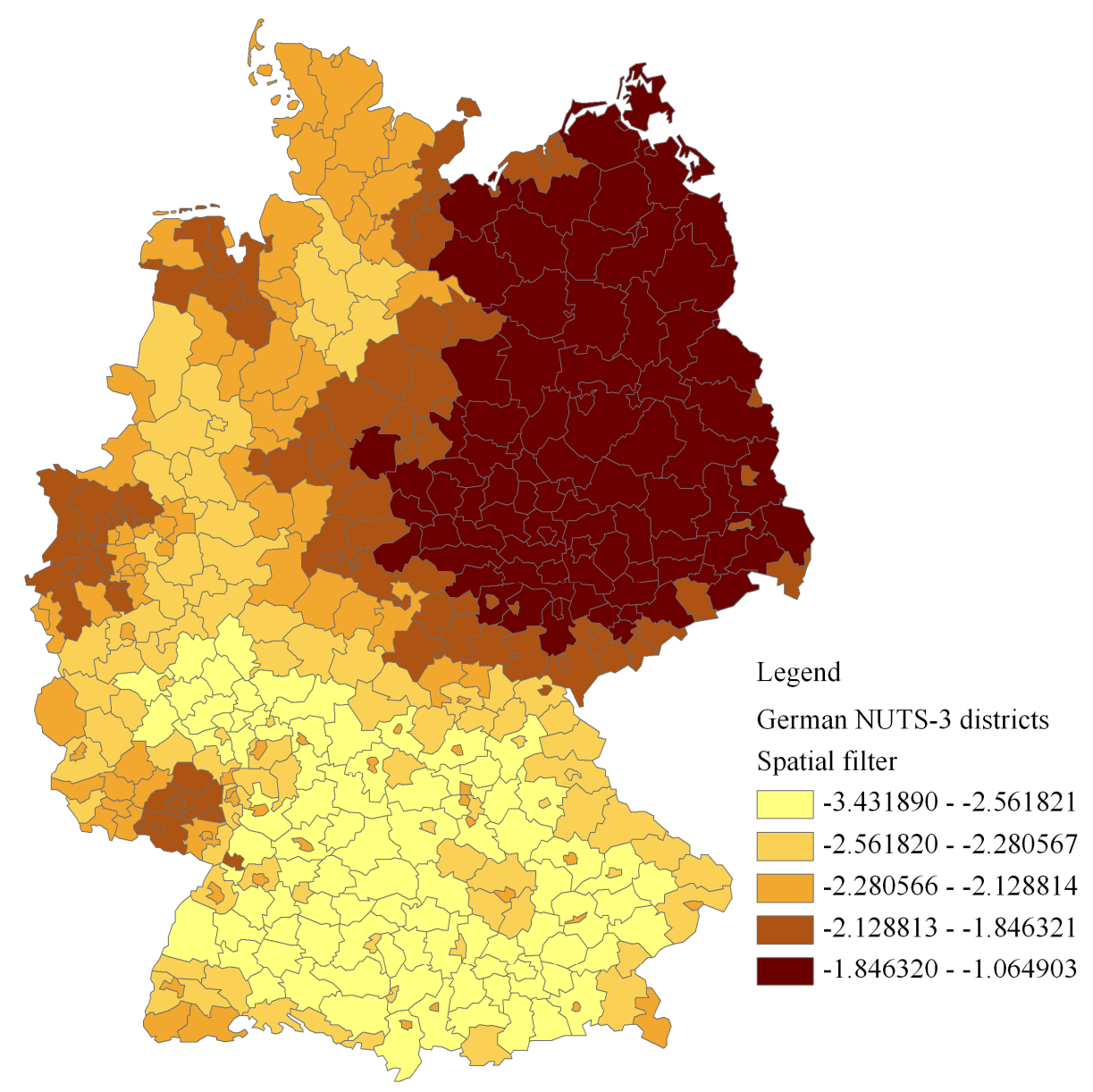

Figure 4 - Graphical visualization of the spatial filter obtained in the case of the rook's definition of contiguity (C-coding scheme) geographic weights matrix, GLMM estimation

With regard to estimation of the model parameters, Table 6 shows that the employed covariates are statistically significant, with regard to the two economic variables (employment and wages) and the spatial filter components. The signs of the former are as expected and consistent with the findings of the separate year-by-year analyses. Meanwhile, the nonsignificant coefficient for population growth suggests that further investigation is needed in order to correctly include demographic aspects in the model specification, and that labour demand factors to some extent may counterbalance the expected labour supply effect. This finding, for example, appears to be consistent with the one by Oud et al. (2008), who carry out a continuous-time spatial-dependence panel analysis of German regional unemployment and population development. The share of variance explained by the GLMM, in terms of pseudo$R^{2}$, is reported in Table 7 .

Table 7 - GLMM fitting, 1996-2002

\begin{tabular}{llllllll}
\hline Year & 1996 & 1997 & 1998 & 1999 & 2000 & 2001 & 2002 \\
\hline Pseudo- $R^{2}$ & 0.937 & 0.959 & 0.960 & 0.952 & 0.944 & 0.939 & 0.921 \\
\hline
\end{tabular}

Results for the GLMM estimation now can be compared with those of selected benchmark models. For purposes of comparison, we estimate three alternative models, each employing, as explanatory variables, the growth rates of wages, employment and population: 
- a simple OLS regression;

- a spatial lag panel model;

- a spatial lag panel model with time fixed effects.

A spatial lag model is computed as follows:

$$
\begin{aligned}
& y=\rho \mathbf{W} y+\mathbf{X} \beta+u, \\
& u \sim(0, \Omega),
\end{aligned}
$$

where the values assumed by the dependent variable $y$ are explained by spatial autoregressive values defined according to a row-standardized geographic weights matrix $\mathbf{W}$, and by the values of the explanatory variables. We choose to compute a spatial lag panel model on the basis of a set of specification search LM tests (Anselin 1988, 2002), carried out year-by-year, ${ }^{6}$ a summary of which is presented in Table 8. The spatial-lag time-fixed-effects specification is an expansion of the spatial lag model illustrated above, in that it also employs year dummies to take into account temporal shocks. Results for the three models appear in Table 9.

\begin{tabular}{|c|c|c|c|c|c|c|c|}
\hline & 1996 & 1997 & 1998 & 1999 & 2000 & 2001 & 2002 \\
\hline LM-lag & Yes & Yes & Yes & Yes & Yes & Yes & Yes \\
\hline LM-error & Yes & Yes & Yes & Yes & Yes & Yes & Yes \\
\hline $\begin{array}{l}\text { Robust LM- } \\
\text { lag }\end{array}$ & Yes & Yes & Yes & Yes & Yes & Yes & Yes \\
\hline $\begin{array}{l}\text { Robust LM- } \\
\text { error }\end{array}$ & No & No & No & No & $\begin{array}{l}\text { Yes } \\
(95 \%)\end{array}$ & No & No \\
\hline $\begin{array}{l}\text { Suggested } \\
\text { model }\end{array}$ & $\begin{array}{l}\text { Spatial } \\
\text { lag }\end{array}$ & $\begin{array}{l}\text { Spatial } \\
\text { lag }\end{array}$ & $\begin{array}{l}\text { Spatial } \\
\text { lag }\end{array}$ & $\begin{array}{l}\text { Spatial } \\
\text { lag }\end{array}$ & $? ?$ & $\begin{array}{l}\text { Spatial } \\
\text { lag }\end{array}$ & $\begin{array}{l}\text { Spatial } \\
\text { lag }\end{array}$ \\
\hline
\end{tabular}

Table 8 - Year-by-year specification search LM test results, 1996-2002

Yes: $H_{0}$ rejected (significant at the 99 per cent level).

No: $H_{0}$ not rejected.

Table 9 - Fit statistics for the benchmark model specifications, 1996-2002

\begin{tabular}{lll}
\hline Model & (Pseudo-) $R^{2}$ & Lag coefficient \\
OLS & 0.3276 & - \\
Spatial lag & 0.7528 & $0.57^{* * *}$ \\
Spatial lag w/ time fixed effects & 0.7934 & $0.57^{* * *}$ \\
\hline
\end{tabular}

99 per cent significant.

Results reported in Table 9 indicate that the fittings of the three benchmark model specifications are poorer than that for the GLMM specification (which has an average pseudo$R^{2}$ of 0.945 ), mostly because its random effects term is a surrogate for various model deficiencies. The signs of the covariates were found to be consistent with those previously observed (Table 4 and Table 6).

Given these results, we can conclude that the GLMM estimation provides a satisfactory statistical description, showing higher fitting than the benchmark models and providing parameter estimates consistent with the expectations. However, implementing more suitable comparison models, which mirror the serial correlation captured by the GLMM, as well as the

\footnotetext{
${ }^{6}$ Ideally, single specification tests could be carried out for the entire time range. We resorted to cross-sectional diagnostics, since the software packages employed (Geoda and R) do not provide such a possibility.
} 
geographically-varying effect of the GLMM intercept, is more desirable. This need for further computations is reflected in the conclusions of this paper.

\section{Conclusions}

In this paper we presented an analysis of German regional unemployment data by means of 'spatial filtering' techniques. The analysis enabled us to uncover underlying spatial structures by selecting sets of 'spatial filters' that significantly explain geographic variations in a given dataset. In addition, we observed subsets of spatial filters that (partially) define spatial structure over time. The spatial filters selected in this case are the ones that were common to the analyses carried out for each year in the 1996-2002 period.

If shown as graphical visualizations, the spatial filters found in our analyses provide certain indications of the geographical distribution of unemployment trends. Using Figure 2 as an example, map (a) can be interpreted as the visualization of a North-South divide, while maps (b), (c), and (d) seem to distinguish particular areas from the rest of the country. Additional eigenvectors (not shown here) show smaller scale patterns of the regional/local spatial dependence structure.

The initial analysis then was repeated, in Section 4.3, by introducing into the initial spatial statistical framework three explanatory variables with socio-economic meaning: wages, employment and population. We constructed new sets of spatial filters, which, in this case, are the result not only of the analysis of the dependent variable, but also of the covariates. We show, in this case as well, the possibility to select a time-invariant spatial filter subset that accounts for spatial structures in all the years of data analysed. Subsequently, a GLMM, estimated via a penalized quasi-likelihood procedure, was used in order to model unemployment rates by means of the covariates and the spatial filter components jointly. We show that the GLMM estimation provides a high level of statistical reliability, as well as parameter estimates consistent with the literature.

The results obtained in this paper illustrate spatial structure underlying georeferenced unemployment data. Nevertheless, future research along these lines is needed. On the empirical side, a proxy of spatial economic linkages could be employed as an alternative to a spatial weights matrix based on a contiguity rule. Also, the analysis of unemployment levels has its counterpart in that of employment growth rates. Future investigations should address this objective. Furthermore, the analysis of unemployment levels should be more formally concerned with the joint analysis of factors pertaining to labour supply and demand. While the introduction in this analysis of three covariates is a first step, future investigations need to address this issue, for example adopting a full regional labour markets model, such as the one of Blanchard and Katz (1992). On the methodological side, a comparison of the performance of the spatial statistical approach with other conventional spatial econometrics methods, as well as with non-linear approaches, such as neural networks, is desirable. Mixed neural networks/spatial filtering approaches also should be tested. Policy-wise, more in-depth examination of the spatially-filtered GLMM residuals resulting from the analysis should be carried out, in order to fully grasp the benefits of the methodology applied.

The analyses presented in this paper have highlighted the relevance - and most importantly the persistence - of spatial structures in German regional unemployment rates (and, we could generalize, in the corresponding labour markets). Our finding of common spatial filters for different years is a reflection of this general stability. Consequently, the spatial filtering technique employed here is one of several useful tools that can be deployed in the analysis of regional disparities. 
Finally, a detailed spatial filter analysis of the individual covariates used here also is desirable, for comparison purposes and to attain a better understanding of the role played by spatial structure.

\section{References}

Akaike H. (1974) A New Look at the Statistical Model Identification. IEEE Transactions on Automatic Control 19 (6), 716-23

Anselin L. (1988) Spatial Econometrics: Methods and Models. Dordrecht Boston: Kluwer Academic Publishers

Anselin L. (2001) Spatial Econometrics. In B.H. Baltagi (ed.), A Companion to Theoretical Econometrics (pp. 310-30). Malden: Blackwell

Anselin L. (2002) Under the Hood: Issues in the Specification and Interpretation of Spatial Regression Models. Agricultural Economics 27 (3), 247-67

Anselin L., R.J.G.M. Florax and S.J. Rey (eds) (2004) Advances in Spatial Econometrics. Berlin Heidelberg New York: Springer

Bayer C. and F. Juessen (2007) Convergence in West German Regional Unemployment Rates. The German Economic Review 8 (4), 510-35

Blanchard O.J. and L.F. Katz (1992) Regional Evolutions. Brookings Papers on Economic Activity 1, 1-75

Bockstael N.E. (1996) Economics and Ecological Modeling: The Importance of a Spatial Perspective. American Journal of Agricultural Economics 78 (5), 1168-80

Breslow N.E. and D.G. Clayton (1993) Approximate Inference in Generalized Linear Mixed Models. Journal of the American Statistical Association 88 (421), 9-25

Carlino G.A. and E.S. Mills (1987) The Determinants of County Growth. Journal of Regional Science 27 (1), 39-54

Cliff A.D. and J.K. Ord (1981) Spatial Processes: Models \& Applications. London: Pion

Cracolici M.F., M. Cuffaro and P. Nijkamp (2007) Geographical Distribution of Unemployment: An Analysis of Provincial Differences in Italy. Growth and Change 38 (4), 649-70

Eckey H.-F. (2001) Der Wirtschafliche Entwicklungsstand in den Regionen des Vereinigten Deuschland (Discussion Papers in Economics 20/01). Kassel: University of Kassel, Institute of Economics

Elhorst J.P. (1995) Unemployment Disparities between Regions in the European Union. In H.W. Armstrong and R.W. Vickerman (eds), Convergence and Divergence among European Unions (pp. 209-21). London: Pion

Elhorst J.P., U. Blien and K. Wolf (2007) New Evidence on the Wage Curve: A Spatial Panel Approach. International Regional Science Review 30 (2), 173-91

Evans M. and T. Swartz (2000) Approximating Integrals via Monte Carlo and Deterministic Methods. Oxford: Oxford University Press

Getis A. (1990) Screening for Spatial Dependence in Regression Analysis. Papers of the Regional Science Association 69, 69-81

Getis A. (1995) Spatial Filtering in a Regression Framework: Examples Using Data on Urban Crime, Regional Inequality, and Government Expenditures. In L. Anselin and R.J.G.M. Florax (eds), New Directions in Spatial Econometrics (pp. 172-85). Heidelberg: Springer

Getis A. and D.A. Griffith (2002) Comparative Spatial Filtering in Regression Analysis. Geographical Analysis 34 (2), 130-40

Griffith D.A. (1996) Spatial Autocorrelation and Eigenfunctions of the Geographic Weights Matrix Accompanying Geo-Referenced Data. The Canadian Geographer 40, 351-67 
Griffith D.A. (2000) A Linear Regression Solution to the Spatial Autocorrelation Problem. Journal of Geographical Systems 2, 141-56

Griffith D.A. (2003) Spatial Autocorrelation and Spatial Filtering: Gaining Understanding through Theory and Scientific Visualization. Berlin, New York: Springer

Griffith D.A. (2004) A Spatial Filtering Specification for the Autologistic Model. Environment and Planning A 36 (10), 1791-811

Griffith D.A. (2008) A Comparison of Four Model Specifications for Describing Small Heterogeneous Space-Time Datasets: Sugar Cane Production in Puerto Rico, 1958/591973/74. Papers in Regional Science 87 (3), 341-55

Griffith D.A. and J.H. Paelinck (2009) Specifying a Joint Space- and Time-Lag Using a Bivariate Poisson Distribution. Journal of Geographical Systems (forthcoming)

Haining R. (1991) Bivariate Correlation and Spatial Data. Geographical Analysis 23, 210-27

Kelejian H.H. and I.R. Prucha (1998) A Generalized Spatial Two-Stage Least Squares Procedure for Estimating a Spatial Autoregressive Model with Autoregressive Disturbances. Journal of Real Estate Finance and Economics 17 (1), 99-121

Kelejian H.H. and I.R. Prucha (1999) A Generalized Moments Estimator for the Autoregressive Parameter in a Spatial Model. International Economic Review 40, 50933

Kosfeld R. and C. Dreger (2006) Thresholds for Employment and Unemployment. A Spatial Analysis of German Regional Labour Markets 1999-2000. Papers in Regional Science 85 (4), 523-42

Lacombe D.J. (2004) Does Econometric Methodology Matter? An Analysis of Public Policy Using Spatial Econometric Techniques. Geographical Analysis 36 (2), 105-18

Lee L.-F. (2004) Asymptotic Distributions of Quasi-Maximum Likelihood Estimators for Spatial Autoregressive Models. Econometrica 72, 1899-925

Longhi S. and P. Nijkamp (2007) Forecasting Regional Market Developments under Spatial Autocorrelation. International Regional Science Review 30 (2), 100-51

López-Bazo E., T. del Barrio and M. Artis (2002) The Regional Distribution of Spanish Unemployment: A Spatial Analysis. Papers in Regional Science 81 (3), 365-89

McCullogh C.E., S.R. Searle and J.M. Neuhaus (2008) Generalized, Linear, and Mixed Models. Hoboken: John Wiley \& Sons

McQuarrie A.D.R. and C.-L. Tsai (1998) Regression and Time Series Model Selection. Singapore River Edge: World Scientific

Niebuhr A. (2003) Spatial Interaction and Regional Unemployment in Europe. European Journal of Spatial Development 5

Oud J., H. Folmer, R. Patuelli and P. Nijkamp (2008) A Spatial-Dependence Continuous-Time Model for Regional Unemployment Analysis in Germany. Lugano: Quaderno N. 0811, Faculty of Economics, University of Lugano

Patuelli R. (2007) Regional Labour Markets in Germany: Statistical Analysis of SpatioTemporal Disparities and Network Structures. Unpublished Ph.D. Thesis, VU University Amsterdam, Amsterdam

Patuelli R., A. Reggiani, P. Nijkamp and U. Blien (2006a) New Neural Network Methods for Forecasting Regional Employment: An Analysis of German Labour Markets. Spatial Economic Analysis 1 (1), 7-30

Patuelli R., D.A. Griffith, M. Tiefelsdorf and P. Nijkamp (2006b) The Use of Spatial Filtering Techniques: The Spatial and Space-Time Structure of German Unemployment Data (TI Discussion Paper 06-049/3). Amsterdam: VU University Amsterdam

Tiefelsdorf M. and B. Boots (1995) The Exact Distribution of Moran's I. Environment and Planning A 27, 985-99 
Tiefelsdorf M. and D.A. Griffith (2007) Semiparametric Filtering of Spatial Autocorrelation: The Eigenvector Approach. Environment and Planning A 39 (5), 1193-221

Tiefelsdorf M., D.A. Griffith and B.N. Boots (1999) A Variance Stabilizing Coding Scheme for Spatial Link Matrices. Environment and Planning A 31, 165-80

Venables W.N. and B.D. Ripley (2002) Modern Applied Statistics with S (4th ed.). New York: Springer

Weinhold D. (2002) The Importance of Trade and Geography in the Pattern of Spatial Dependence of Growth Rates. Review of Development Economics 6 (3), 369-82

Williams D.A. (1982) Extra-Binomial Variation in Logistic Linear Models. Applied Statistics $31(2), 144-8$

Wolfinger R. and M. O'Connell (1993) Generalized Linear Mixed Models: A PseudoLikelihood Approach. Journal of Statistical Computation and Simulation 48 (3-4), $233-43$ 


\section{QUADERNI DELLA FACOLTÀ}

1998:

P. Balestra, Efficient (and parsimonious) estimation of structural dynamic error component models

1999:

M. Filippini, Cost and scale efficiency in the nursing home sector : evidence from Switzerland

L. Bernardi, I sistemi tributari di oggi : da dove vengono e dove vanno

L.L. Pasinetti, Economic theory and technical progress

G. Barone-Adesi, K. Giannopoulos, L. Vosper, VaR without correlations for portfolios of derivative securities

G. Barone-Adesi, Y. Kim, Incomplete information and the closed-end fund discount

G. Barone-Adesi, W. Allegretto, E. Dinenis, G. Sorwar, Valuation of derivatives based on CKLS interest rate models

M. Filippini, R. Maggi, J. Mägerle, Skalenerträge und optimale Betriebsgrösse bei den schweizerische Privatbahnen

E. Ronchetti, F. Trojani, Robust inference with GMM estimators

G.P. Torricelli, I cambiamenti strutturali dello sviluppo urbano e regionale in Svizzera e

nel Ticino sulla base dei dati dei censimenti federali delle aziende 1985, 1991 e 1995

2000:

E. Barone, G. Barone-Adesi, R. Masera, Requisiti patrimoniali, adeguatezza del capitale e gestione del rischio

G. Barone-Adesi, Does volatility pay?

G. Barone-Adesi, Y. Kim, Incomplete information and the closed-end fund discount

$\mathrm{R}$. Ineichen, Dadi, astragali e gli inizi del calcolo delle probabilità

W. Allegretto, G. Barone-Adesi, E. Dinenis, Y. Lin, G. Sorwar, A new approach to check the free boundary of single factor interest rate put option

G.D.Marangoni, The Leontief Model and Economic Theory

B. Antonioli, R, Fazioli, M. Filippini, // servizio di igiene urbana italiano tra concorrenza e monopolio

L. Crivelli, M. Filippini, D. Lunati. Dimensione ottima degli ospedali in uno Stato federale

L. Buchli, M. Filippini, Estimating the benefits of low flow alleviation in rivers: the case of the Ticino River

L. Bernardi, Fiscalità pubblica centralizzata e federale: aspetti generali e il caso italiano attuale

M. Alderighi, R. Maggi, Adoption and use of new information technology

F. Rossera, The use of log-linear models in transport economics: the problem of

commuters' choice of mode

2001:

M. Filippini, P. Prioni, The influence of ownership on the cost of bus service provision in

Switzerland. An empirical illustration

B. Antonioli, M. Filippini, Optimal size in the waste collection sector

B. Schmitt, La double charge du service de la dette extérieure

L. Crivelli, M. Filippini, D. Lunati, Regulation, ownership and efficiency in the Swiss

nursing home industry

S. Banfi, L. Buchli, M. Filippini, Il valore ricreativo del fiume Ticino per i pescatori

L. Crivelli, M. Filippini, D. Lunati, Effizienz der Pflegeheime in der Schweiz 
2002:

B. Antonioli, M. Filippini, The use of a variable cost function in the regulation of the Italian water industry

B. Antonioli, S. Banfi, M. Filippini, La deregolamentazione del mercato elettrico svizzero e implicazioni a breve termine per l'industria idroelettrica

M. Filippini, J. Wild, M. Kuenzle, Using stochastic frontier analysis for the access price regulation of electricity networks

G. Cassese, On the structure of finitely additive martingales

2003:

M. Filippini, M. Kuenzle, Analisi dell'efficienza di costo delle compagnie di bus italiane e svizzere

C. Cambini, M. Filippini, Competitive tendering and optimal size in the regional bus transportation industry

L. Crivelli, M. Filippini, Federalismo e sistema sanitario svizzero

L. Crivelli, M. Filippini, I. Mosca, Federalismo e spesa sanitaria regionale : analisi empirica per i Cantoni svizzeri

M. Farsi, M. Filippini, Regulation and measuring cost efficiency with panel data models : application to electricity distribution utilities

M. Farsi, M. Filippini, An empirical analysis of cost efficiency in non-profit and public nursing homes

F. Rossera, La distribuzione dei redditi e la loro imposizione fiscale : analisi dei dati fiscali svizzeri

L. Crivelli, G. Domenighetti, M. Filippini, Federalism versus social citizenship :

investigating the preference for equity in health care

M. Farsi, Changes in hospital quality after conversion in ownership status

G. Cozzi, O. Tarola, Mergers, innovations, and inequality

M. Farsi, M. Filippini, M. Kuenzle, Unobserved heterogeneity in stochastic cost frontier models : a comparative analysis

2004:

G. Cassese, An extension of conditional expectation to finitely additive measures

$\mathrm{S}$. Demichelis, O. Tarola, The plant size problem and monopoly pricing

F. Rossera, Struttura dei salari 2000 : valutazioni in base all'inchiesta dell'Ufficio federale di statistica in Ticino

M. Filippini, M. Zola, Economies of scale and cost efficiency in the postal services : empirical evidence from Switzerland

F. Degeorge, F. Derrien, K.L. Womack, Quid pro quo in IPOs : why book-building is dominating auctions

M. Farsi, M. Filippini, W. Greene, Efficiency measurement in network industries : application to the Swiss railway companies

L. Crivelli, M. Filippini, I. Mosca, Federalism and regional health care expenditures : an empirical analysis for the Swiss cantons

S. Alberton, O. Gonzalez, Monitoring a trans-border labour market in view of liberalization : the case of Ticino

M. Filippini, G. Masiero, K. Moschetti, Regional differences in outpatient antibiotic consumption in Switzerland

A.S. Bergantino, S. Bolis, An adaptive conjoint analysis of freight service alternatives :

evaluating the maritime option

2005:

M. Farsi, M. Filippini, An analysis of efficiency and productivity in Swiss hospitals

M. Filippini, G. Masiero, K. Moschetti, Socioeconomic determinants of regional

differences in outpatient antibiotic consumption : evidence from Switzerland 
2006:

M. Farsi, L. Gitto, A statistical analysis of pain relief surgical operations

M. Farsi, G. Ridder, Estimating the out-of-hospital mortality rate using patient discharge data

S. Banfi, M. Farsi, M. Filippini, An empirical analysis of child care demand in Switzerland

L. Crivelli, M. Filippini, Regional public health care spending in Switzerland : an empirical analysis

M. Filippini, B. Lepori, Cost structure, economies of capacity utilization and scope in Swiss higher education institutions

M. Farsi, M. Filippini, Effects of ownership, subsidization and teaching activities on hospital costs in Switzerland

M. Filippini, G. Masiero, K. Moschetti, Small area variations and welfare loss in the use of antibiotics in the community

A. Tchipev, Intermediate products, specialization and the dynamics of wage inequality in the US

A. Tchipev, Technological change and outsourcing : competing or complementary explanations for the rising demand for skills during the 1980s?

2007:

M. Filippini, G. Masiero, K. Moschetti, Characteristics of demand for antibiotics in primary care : an almost ideal demand system approach

G. Masiero, M. Filippini, M. Ferech, H. Goossens, Determinants of outpatient antibiotic consumption in Europe : bacterial resistance and drug prescribers

R. Levaggi, F. Menoncin, Fiscal federalism, patient mobility and the soft budget constraint : a theoretical approach

M. Farsi, The temporal variation of cost-efficiency in Switzerland's hospitals : an application of mixed models

2008:

Quaderno n. 08-01

M. Farsi, M. Filippini, D. Lunati, Economies of scale and efficiency measurement in

Switzerland's nursing homes

Quaderno n. 08-02

A. Vaona, Inflation persistence, structural breaks and omitted variables : a critical view Quaderno n. 08-03

A. Vaona, The sensitivity of non parametric misspecification tests to disturbance autocorrelation

Quaderno n. 08-04

A. Vaona, STATA tip : a quick trick to perform a Roy-Zellner test for poolability in STATA Quaderno n. 08-05

A. Vaona, R. Patuelli, New empirical evidence on local financial development and growth Quaderno n. 08-06

C. Grimpe, R. Patuelli, Knowledge production in nanomaterials : an application of spatial filtering to regional system of innovation

Quaderno n. 08-07

A. Vaona, G. Ascari, Regional inflation persistence : evidence from Italy Quaderno n. 08-08

M. Filippini, G. Masiero, K. Moschetti, Dispensing practices and antibiotic use Quaderno n. 08-09

T. Crossley, M. Jametti, Pension benefit insurance and pension plan portfolio choice 


\section{Quaderno n. 08-10}

R. Patuelli, A. Vaona, C. Grimpe, Poolability and aggregation problems of regional innovation data : an application to nanomaterial patenting

Quaderno n. 08-11

J.H.L. Oud, H. Folmer, R. Patuelli, P. Nijkamp, A spatial-dependence continuous-time model for regional unemployment in Germany

2009:

Quaderno n. 09-01

J.G. Brida, S. Lionetti, W.A. Risso, Long run economic growth and tourism : inferring from Uruguay

Quaderno n. 09-02

R. Patuelli, D.A. Griffith, M. Tiefelsdorf, P. Nijkamp, Spatial filtering and eigenvector stability : space-time models for German unemployment data 